\title{
Translocation of ErbB receptors into the nucleus
}

\author{
Antonio Villalobo, Clara García-Andrés and Patricia Molina-Ortiz \\ Instituto de Investigaciones Biomédicas. Consejo Superior de Investigaciones Científicas and Universidad Autónoma de Madrid. \\ Madrid.
}

The ErbB receptors are tyrosine kinases that bind a wide variety of ligands. They are implicated in cell proliferation, generation of anti-apoptotic signals, differentiation, and cell migration. The over-expression of different ErbB receptors and/or the expression of aberrant mutant forms are responsible for the development of many human cancers. A simplified view of the mechanism of action of these receptors is that they are triggered when located at the cell surface and/or when present in endosomes. In this review we will discuss a newly emergent, and more complex, picture in which ErbB receptors and their ligands translocate to the cell nucleus where they assume additional functions. The possible involvement of calmodulin in the translocation process will be discussed, as well. The development of new therapeutic strategies targeting the nuclear translocation system and/or the nuclear functions of ErbB receptors could help to control the rapid growth of certain types of tumor cells.

Key words: calmodulin, epidermal growth factor receptor, ErbB2/Neu, ErbB3, ErbB4, nuclear translocation, transcription factors.

Villalobo A, García-Andrés C, Molina-Ortiz P. Translocation of ErbB receptors into the nucleus. Rev Oncol 2003;5(7):381-9

\section{Translocación al núcleo de receptores ErbB}

Los receptores ErbB son tirosina quinasas que unen un extenso número de ligandos y están implicados en proliferación celular, la generación de señales antiapoptóticas, diferenciación y migración celular. La sobreexpresión de diferentes receptores ErbB y/o la expresión de formas aberrantes mutadas son responsables del desarrollo de muchos tipos de cánceres humanos. Una panorámica simplificada del mecanismo de acción de estos receptores nos enseña qué señalizan cuando se encuentran en la superficie celular y/o en endosomas. En esta revisión, sin embargo, explicaremos nuevos y más complejos mecanismos por los que los receptores ErbB y sus ligandos se translocan al núcleo donde ejercen funciones adicionales. La posible implicación de la calmodulina en el proceso de translocación será también discutido. El desarrollo de nuevas estrategias terapéuticas tomando como dianas el sistema de translocación y/o las funciones nucleares de los receptores ErbB, podría ayudar al control del crecimiento rápido en ciertos tipos de células tumorales.

Palabras clave: calmodulina, receptor del factor de crecimiento epidérmico, ErbB2/Neu, ErbB3, ErbB4, translocación nuclear, factores de transcripción.

\section{INTRODUCTION}

The epidermal growth factor receptor (EGFR), also named ErbB1/HER1, belongs to the ErbB receptor family, which is formed by three additional members including ErbB2/Neu/HER2, ErbB3/HER3 and ErbB4/HER4. These receptors are highly glycosylated 185-170 kDa proteins located at the plasma membrane and have a single transmembrane segment. They bind an extensive family of polypeptide ligands at its extracellular re-

\footnotetext{
Correspondence: Dr. A. Villalobo, MD, PhD.

Instituto de Investigaciones Biomédicas.

Consejo Superior de Investigaciones Científicas.

and Universidad Autónoma de Madrid.

c/ Arturo Duperier 4, E-28029 Madrid, Spain.

E-mail: antonio.villalobo@iib.uam.es

Received 30 May 2003; Revised 18 July 2003; Accepted 21 July 2003.
}

gion, inducing their homo- or heterodimerization, and the activation of its intrinsic tyrosine kinase located in their intracellular region ${ }^{1-3}$. ErbB3, however, lacks a functional tyrosine kinase domain, and ErbB2 does not have a known direct ligand, although both receptors are able to signal upon interaction between themselves or with other ErbB family members. The combinatorial interaction of different ErbB receptors with distinct ligands form an array of signaling complexes able to evoke diverse physiological responses ${ }^{4}$. Interestingly, the ErbB3:ErbB2 heterodimer is one of the most potent signaling complexes ${ }^{5}$. ErbB receptors generate multiple cellular responses such as cell proliferation, survival signals, differentiation, and cell motility. Over-expression and/or the occurrence of a variety of mutations in different ErbB receptors are observed in a significant number of human tumors ${ }^{6,7}$. 
A classical view of the signaling mechanisms elicited by ErbB receptors depicts the following simplified picture: plasma membrane-located receptors are activated upon dimerization induced after binding of an extracellular ligand, what is followed by its trans(auto)phosphorylation, and the recruitment of signaling molecules bearing Src homology 2 (SH2) or phosphotyrosine binding (PTB) domains at their autophosphorylated tyrosine residues. These events generate the activation of a panoply of signaling pathways bringing about the translocation of different signaling proteins into the nucleus, which are involved in the transcriptional regulation of multiple genes required for specific cellular responses ${ }^{8,9}$. Thereafter, the receptors are internalized at clathrin-coated pits, and located at endosomes, what is subsequently followed by their degradation at lysosomes to abrogate signaling, or their recycling back to the cell surface ${ }^{10}$. Ingenious methods have been developed, however, to show that endosome-located receptors are also able to generate signaling events ${ }^{11}$. Nevertheless, in this review we shall discuss, a radical different picture on the functionality of ErbB receptors, as they are able to translocate to the nucleus to exert additional functional roles, opening a new paradigm on how these receptors operate in a much more complex manner in living cells.

\section{LOCALIZATION OF ErbB RECEPTOR LIGANDS INTO THE NUCLEUS}

Various polypeptide growth factors have been identified within the nucleus of multiple cell types, and in some intriguing cases associating themselves to the nucleoli $^{12,13}$. This has caused an exciting debate about their functional role at this location ${ }^{13,14}$. In regard to ErbB receptor ligands, the epidermal growth factor $(\mathrm{EGF})^{15-21}$, amphiregulin (AR $)^{15,22}$, schwannoma-derived growth factor (SDGF) ${ }^{23}$, and most recently heregulin-\$1 (HRGß1) ${ }^{24}$, have been found in the nucleus, and/or to bind to DNA. Although the nuclear localization of HRGß1 was first demonstrated in a human breast adenocarcinoma cell line ${ }^{24}$, neither endogenous or exogenous HRGß1 was found to translocate into the nucleus of nonmalignant human mammary epithelial cells ${ }^{25}$.

The first observation on the nuclear localization of EGF took place in cultured cells, and it was favored by the inhibition of lysosomal degradation using chloroquine ${ }^{15}$. Thereafter, further nuclear localization of EGF was observed in different cell types ${ }^{16,18,19}$, and in regenerating liver ${ }^{17,20}$, a rapid proliferating tissue. Nuclear EGF is tightly bound to chromatin, where it appears to be coupled to a $250-230 \mathrm{kDa}$ protein ${ }^{16,18}$. In regenerating liver, EGF is also associated to a high molecular mass complex ${ }^{17}$, and binds to nuclear EGFR with similar affinity than to receptors located in the plasma membrane ${ }^{20}$.
AR itself contains two putative nuclear localization sequences (NLS) and it has been shown indeed to localize in the nucleus of normal and tumor cells, with a preferential nucleolar localization in the latter ${ }^{22,26}$. Two proteins of $205 \mathrm{kDa}$ and $120 \mathrm{kDa}$ that putatively could bind to the NLS of AR, have been identified ${ }^{22}$. SDGF also contains a nuclear targeting motif, and this growth factor has been shown to bind to $(\mathrm{A}+\mathrm{T})$ rich DNA sequences ${ }^{23}$. Although the precise functions of these growth factors in the nucleus has yet to be determined, it has been shown that HRGß1 not only is translocated to the nucleus but it appears to up-regulate the expression of c-myc in human adenocarcinoma cells ${ }^{24}$. Likewise, SDGF seems to induce the transcription of early genes involved in cell proliferation, such as nerve growth factor I-A and c-fos ${ }^{23}$. An interesting question pending to be answered is whether the observed transcriptional activity is entirely due to the nuclear growth factors, or there is a participation of their cognate receptors also located in the nucleus.

\section{TRANSLOCATION OF ErbB RECEPTORS INTO THE NUCLEUS}

It is now apparent that the four members of the ErbB receptor family are capable to be translocated into the cell nucleus, as we shall discuss herein after, although the information concerning ErbB2 and ErbB3 is far more scarce than that for EGFR and ErbB4. This seemingly unorthodox view has been received with a mixture of great excitement and some caution by the scientific community, because the implied overhaul of a set of text-book ideas on how these receptors signal to the nucleus via indirect complex arrays of well established signaling pathways. In reality, the new findings describe a more complicated picture, where ErbB receptors are also able to directly perform different functions within the nucleus. Thus, several articles commenting the significance and importance of nuclear ErbB receptors have been recently published in very visible journals ${ }^{14,27-29}$.

\section{EGFR}

A hint about a possible functional role of an ErbB receptor in the nucleus was first described with purified EGFR, as it was shown to be able to interact and nicks supercoilled double-stranded DNA in an ATPstimulated manner ${ }^{30}$. Although the nicking process was latter demonstrated to be due to an associated protein and not to EGFR itself ${ }^{31}$, the binding of this receptor to DNA represented the first unexpected observation of a more complex drama to start to be unfolded years later.

Although the association of EGFR to the nuclear envelop has been occasionally noticed ${ }^{32}$, this receptor 
has been clearly detected inside the nucleus of multiple normal cells, and most conspicually in highly proliferating cells, such as in regenerating liver after partial hepatectomy ${ }^{20,33}$, hepatocellular proliferating cells after bile duct ligation ${ }^{34}$, uterus from pregnant mice ${ }^{35}$, 10-days old mouse embryos ${ }^{35}$, normal human mouth mucosa basal cells ${ }^{35}$, and cells from thyroid tissue of Graves' disease patients ${ }^{21}$. Additionally, nuclear EGFR has been found in cells from human tumor samples including: adrenocortical carcinoma ${ }^{36}$, transitional cell bladder cancer ${ }^{37}$, thyroid follicular adenoma and carcinoma but not papillary carcinoma ${ }^{21}$, oral cancer ${ }^{35}$, and breast cancer ${ }^{35}$; premalignant human papillomavirus lesions of the cervix ${ }^{38}$; and human tumor cell lines including: SW948 colorectal carcinoma cells $^{18}$, squamous carcinoma HN5 cells ${ }^{39}$, epidermoid carcinoma A431 cells ${ }^{35}$, and breast cancer MDA-MB-468 cells ${ }^{35}$.

The addition of EGF or transforming growth factor- $\alpha$ (TGF- $\alpha$ ) induce a time-dependent translocation of the plasma membrane-located receptor into the nucleus $^{35,39,40}$, and the presence of serum in the cell cultures appears to favor the EGF-dependent translocation process ${ }^{39,40}$. The full-length EGFR, and not a proteolytically-processed cytoplasmic domain of the receptor, is the actual translocated species ${ }^{35,39}$. Moreover, the nuclear EGFR appears to be highly phosphorylated at tyrosine residues ${ }^{35}$. It has been argued that the observed EGFR could be located at the perinuclear endoplasmic reticulum (ER) network, and that the confocal microscopy sections used in its detection could be too thick to have adequate resolution $^{41}$. These objections, however, were reasonable answered with further convincing experiments showing co-localization between nuclear EGFR, DAPI staining, and a nuclear marker protein (lamin), as well as the absence of co-localization of the EGFR with ER protein markers (Bip/GRP78 and calnexin $)^{42}$.

We have determined in living cells transfected with a chimera between the human EGFR and the green fluorescence protein (EGFR-GFP) using fluorescence confocal microscopy, that when the receptor is internalized upon EGF addition fluorescent spots are observable in different nuclear planes after prolonged exposure to the growth factor (fig. 1). It is difficult, however, to ascertain whether the fluorescent spots observed in the nuclear region represent intranuclear EGFR-GFP. Nevertheless, to maximize the accumulation of EGFR-GFP into the nucleus we used leptomycin B, an inhibitor of the nuclear export chromosomal region maintenance 1 (CRM1) receptor. Thus, blocking the nuclear export system, we have obtained convincing evidence of the nuclear localization of the chimera receptor, as the fluorescence was clearly associated to the nucleoli after $1 \mathrm{~h}$ exposure to EGF (fig. 2). Although the observed event was

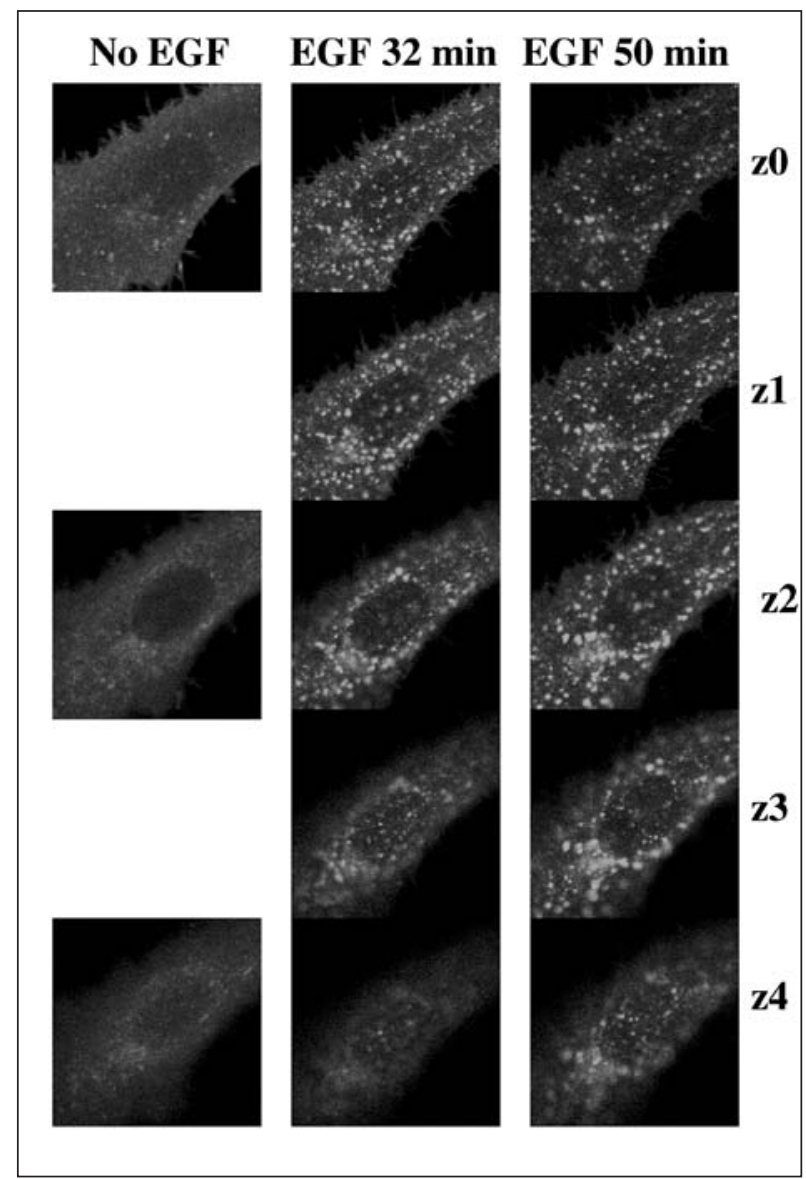

Fig. 1. EGF-dependent internalization of EGFR-GFP in living cells. Porcine aortic endothelial cells stable transfected with a human EGFR-GFP chimera (PAE/EGFR-GFP cells), prepared by Dr. Alexander Sorkin (University of Colorado, Denver CO, USA), were maintained overnight in the absence of serum, and observed in a Leica SP2 confocal microscope before and after stimulation with $10 \mathrm{nM}$ EGF for the indicated times. A 63x HCX Plapo objective with zoom was employed, recording the images in the $x, y, z-m o d e$ using the $488 \mathrm{~nm}$ argon laser, the rsp 500 filter, an Airi 1 pinhole with automatic setting, and focusing the planes at $1 \mathrm{\mu m}$ intervals from the bottom (z0) to the top (z4) to obtain the stacks. Three or five planes were recorded, respectively, before and after EGF stimulation. Notice the massive accumulation of fluorescence in endosomes because the EGF-induced internalization of the receptor, and the presence of conspicuous fluorescent spots in the nuclear region after EGF stimulation.

EGF-dependent, and therefore likely to have a physiological meaning, further experiments should be performed to ascertain that the observed nucleolar fluorescence corresponds to the EGFR-GFP chimera, and not to processed free GFP. This observation suggests that EGFR is able to locate at the nucleoli, where it may play important functional roles on mRNA and/or rRNA processing. This new finding is in agreement with similar observations on the localization of ErbB3 at the nucleoli ${ }^{25}$. 

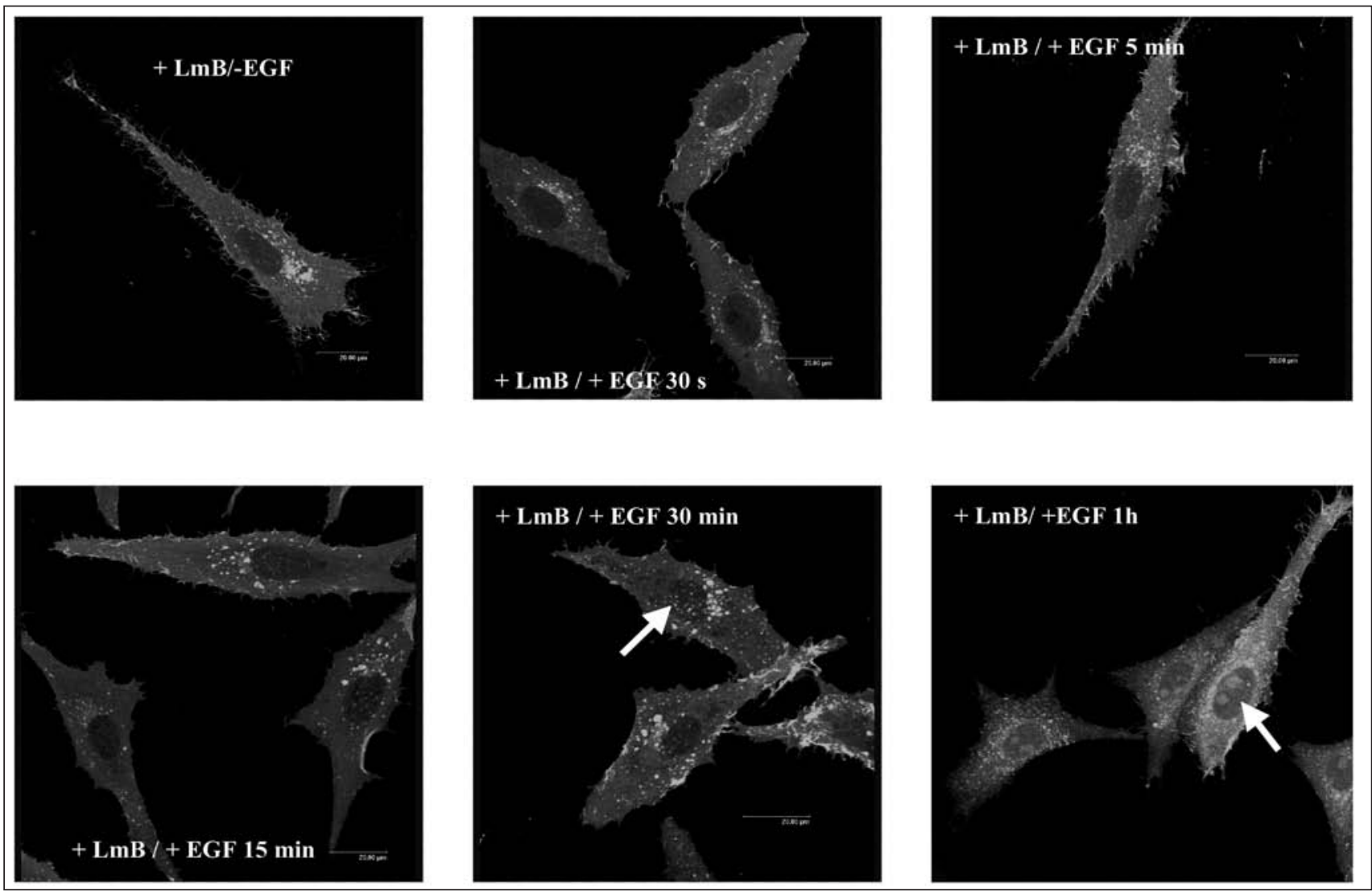

Fig. 2. EGF-dependent association of EGFR-GFP to the nucleoli. Serum-starved PAE/EGFR-GFP cells were maintained $4 \mathrm{~h}$ in the presence of $37 \mathrm{nM}$ leptomycin B (LmB). Thereafter, $10 \mathrm{nM}$ EGF was added (where indicated) and incubated for the indicated times, fixed with $4 \%$ paraformaldehyde, and observed by confocal microscopy as in figure 1, except that no zoom, and only the $x, y$-mode was used. The arrows point to disperse fluorescent spots at the nucleus (30 min frame), and fluorescence associated to the nucleoli (1 $\mathrm{h}$ frame).

\section{ErbB2}

ErbB2 has been shown to translocate to the nucleus as detected in preparations of isolated nuclei by Western blot analysis and immunofluorescence, and the nuclear translocated receptor was shown to be phosphorylated at tyrosine residues in greater extent than its non-nuclear counterpart ${ }^{43}$.

\section{ErbB3}

The full-length ErbB3 has also been shown to translocate into the nucleus of both tumor and nonmalignant mammary epithelial cells, and the presence of leptomycin B enhances its nuclear localization ${ }^{25}$. Moreover, ErbB3 was found to be associated to the nucleoli of cells induced to attain epithelial polarity upon selective growth on permeable filters rather than in a solid substrate ${ }^{25}$. Blocking the production of endogenous HRGß1 with a neutralizing antibody facilitates the association of ErbB3 to the nucleoli, and conversely, the addition of exogenous HRGß1 induces the translocation of the receptor from the nucleoli to the nucleoplasm, and thereafter to the cytoplasm 25 . From two potential NLSs, the motif RRRR, located in the C-terminal region of the mature ErbB3 (residues 1183-1186), was identified as the functional NLS of the receptor by three different methods: a) directing to the nucleus a chimera of the enhanced green fluorescence protein (EGFP) with the C-terminal segment of ErbB3 containing the NLS; b) abrogating its nuclear transport after site-directed mutagenesis of the NLS; and c) transferring a sequence containing the NLS to chicken pyruvate kinase, a cytoplasmic protein, and observing its nuclear localization ${ }^{25}$.

\section{ErbB4}

Occasional immunostaining of nuclei using anti-ErbB4 antibodies was first noticed in some kidney preparations $^{44}$. Thereafter, a systematic study on 178 human invasive breast tumors demonstrated than $49 \%$ of those gave positive nuclear immunostaining using two antibodies against the cytosolic region of ErbB4, whereas only $<5 \%$ of the morphological nor- 
mal breast epithelium adjacent to the tumor gave a positive nuclear signal ${ }^{45}$. This method could therefore be used to better delineate the area of malignancy within a biopsy sample. Afterwards, it was shown that ErbB4 is proteolitically processed upon HRG stimulation or protein kinase $\mathrm{C}$ activation with phorbol esters. The sequential proteolysis is carried out first by the metalloprotease TACE, releasing most of its ectodomain, and thereafter by $\gamma$-secretase, producing an intramembrane cleavage that releases the cytosolic region of the receptor that is translocated to the nucleus as demonstrated using two ErbB4 ${ }_{\text {cyt }}{ }^{-G F P}$ constructs ${ }^{46,47}$.

The $\gamma$-secretase is a high molecular mass complex formed by the endoproteolyzed form of presenilin, responsible for its catalytic activity, plus nicastrin, APH-1 and PEN-2, three additional essential cofactor proteins ${ }^{48}$. Thus, presenilin inhibitors, or the expression of a dominant negative presenilin mutant, prevent ErbB4 processing and the nuclear localization of its cytoplasmic domain ${ }^{46,47}$. Moreover, the use of leptomycin B favors the nuclear localization of the cytoplasmic domain of ErbB4, suggesting that this receptor segment shuttles between the nucleus and the cytoplasm $^{46}$.

\section{THE NUCLEAR TRANSLOCATION MECHANISM}

An unresolved problem is to determine how a fulllength receptor, as it has been proposed to occur with the $\mathrm{EGFR}^{35,39}$ and $\operatorname{ErbB}^{25}$, containing its highly hydrophobic transmembrane segment, is able to undergo nuclear translocation through the nuclear pore via the Ran/importin system. To explain the nuclear translocation several putative mechanisms have been suggested.

In the first one, spliced variants lacking the transmembrane domain, rather than the native molecule, could be the actual translocated species, although not naturally occurring EGFR variants with these characteristics has yet been found ${ }^{14}$. Nevertheless, a specific Val to Glu point mutation in the transmembrane domain of ErbB2, that changes its high hydrophobic character, has been found in a set of tumor cell lines containing activated ErbB2 ${ }^{49}$. Moreover, a recombinant EGFR lacking its transmembrane domain has been shown to translocate to the nucleus in transfected cells, but only when the wild type EGFR was co-transfected ${ }^{50}$. The second plausible proposed mechanism suggests that the hydrophobicity of the transmembrane domain of the receptor could be masked by its interaction with a chaperone-like protein or other accessory protein(s) ${ }^{14,39}$. Finally, a direct fusion of the endosomal and nuclear membranes could occur ${ }^{39}$. Although these interesting speculations are worth to be explored further, hard experimental evidence is needed to assert the actual molecular mechanism featuring this puzzling translocation process.
In the case of ErbB4, however, the translocation of its cytosolic domain after the sequential proteolytic processing of the plasma membrane bound receptor is more easy to envisage, as its transmembrane segment is absent in the translocated species ${ }^{46}$. At present, it is not known whether the full-length $\operatorname{ErbB} 2$, or only its cytosolic region, is the actual species translocated to the nucleus.

\section{POTENTIAL ROLE OF CALMODULIN REGULATING THE TRANSLOCATION OF ErbB RECEPTORS INTO THE NUCLEUS}

Calmodulin has been implicated in the nuclear import machinery. So, it has been described the existence of a calmodulin-stimulated GTP-independent nuclear import system ${ }^{51}$. This transport pathway appears to be operative when the cytosolic concentration of free $\mathrm{Ca}^{2+}$ increases in stimulated cells, conditions in which the classical GTP-dependent transport system becomes inhibited ${ }^{51}$.

A putative NLS in the EGFR has been proposed to exist in the cytosolic juxtamembrane region of the receptor (residues 645-657) ${ }^{35,39}$, and identified as such by fusing this polypeptidic segment with $\beta$-galactosidase and observing its direct entry into the nucleus ${ }^{35}$. Interestingly, we have previously determined that the overlapping sequence (residues 645-660) constitutes the calmodulin-binding domain (CaM-BD) of the EGFR $^{52,53}$, observation that has been confirmed by others $^{54}$ (fig. 3). Calmodulin directly interacts with the EGFR modulating its tyrosine kinase activity ${ }^{52,55}$, and calmodulin also intervenes in the sorting and recycling of internalized receptors ${ }^{56}$. We have proposed,

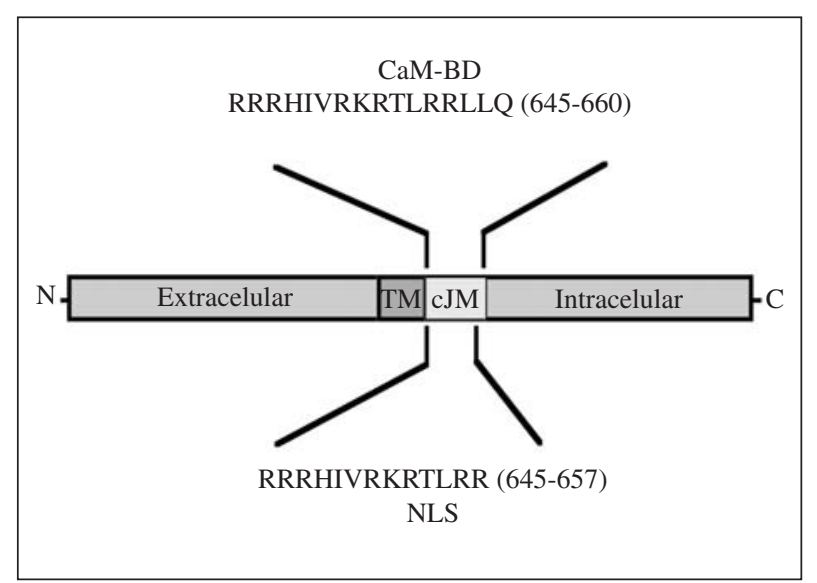

Fig. 3. The calmodulin-binding domain of the EGFR coincides with its nuclear localization sequence. The cartoon represents the general structure of the EGFR in which the overlapping sequences corresponding to the calmodulinbinding domain (CaM-BD) ${ }^{52-54}$, and the nuclear localization sequence (NLS) ${ }^{35,39}$, located in the cytosolic juxtamembrane region (cJM) immediately following the transmembrane domain (TM), are indicated using the single-letter amino acid code. 
therefore, that calmodulin could have an additional role regulating the nuclear translocation of the EGFR, perhaps occluding its NLS when this process is required to be prevented ${ }^{57}$. In this context, it is worth to mention that nuclear translocation of the transcription factor c-Rel is prevented by its interaction with calmodulin $^{58}$.

In the case of ErbB4, the motif KKKR (residues 656659 of the mature receptor), also located in the cytosolic juxtamembrane region, has been suggested to constitute, among other possible motifs (PFVSRRK and PEKAKKA), a putative NLS ${ }^{45}$. This motif is within the proposed CaM-BD of ErbB4 (residues 651666), as this domain has high homology with the CaM-BD of the EGFR ${ }^{53,57}$. This suggests that calmodulin could likewise be involved in the regulation of the translocation of the cytosolic segment of ErbB4 into the nucleus.

In contrast, and as discussed above, the NLS of ErbB3 (RRRR motif) is not located in its cytosolic juxtamembrane region but in its C-terminus ${ }^{25}$. The calmodulin-binding capacity of ErbB3 has not yet been determined. However, although it cannot be excluded that ErbB3 binds calmodulin, the ortholog region of ErbB3 corresponding to the CaM-BD of EGFR has less homology than similar region in other ErbB family members ${ }^{53,57}$. This suggests that if the putative CaM-BD of ErbB3 were inactive or greatly impaired, a different NLS could have been selected in the course of evolution.

\section{FUNCTIONAL ROLE OF ErbB RECEPTORS IN THE NUCLEUS}

As discussed earlier ${ }^{27,28}$, the most obvious advantage of the translocation of ErbB receptors into the nucleus is that they can deliver specific signals avoiding the promiscuity of common signaling pathways shared by other plasma membrane located receptors. Within the nucleus, it has been proposed ${ }^{14}$ that there are four possible functional roles to be exerted by ErbB receptors: a) transcriptional gene regulation; b) chromatin remodeling; c) phosphorylation of nuclear proteins; and d) RNAs processing, particularly at the nucleoli (fig. 4).

The most exciting finding about the nuclear EGFR is that it may acts as a transcription factor or a transcriptional co-activator. Thus, nuclear EGFR binds in vivo to $(\mathrm{A}+\mathrm{T})$-rich consensus sequences in the promoter region of cyclin $\mathrm{D} 1, \mathrm{a}_{1}$ cell-cycle regulator, and the C-terminal tail of the receptor containing a PRR motif is responsible for its transcriptional activity $^{35}$. As the whole cytosolic region of the EGFR has a poor transcriptional activity as compared with its Cterminal end, it is possible that a negative regulatory site present in its tyrosine kinase domain could be responsible for the observed difference in transcrip-

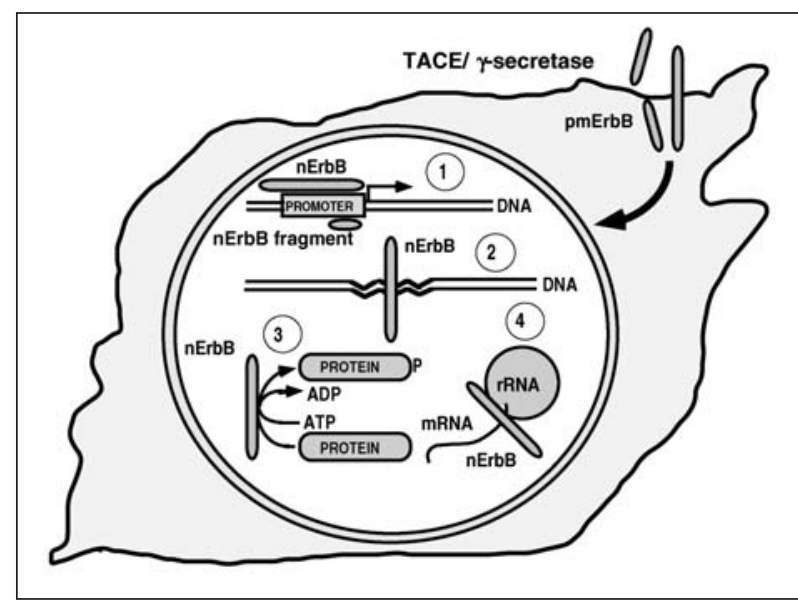

Fig. 4. Putative functional roles of ErbB receptors in the nucleus. A plasma membrane-located ErbB receptor (pmErbB) or its cytosolic domain, released upon sequential proteolysis by the TACE $/ \gamma$-secretase system (see text), are internalized and translocated to the nucleus by an unknown mechanism. As previously discussed ${ }^{14}$, the proposed functional roles of ErbB receptors located in the nucleus (nErbB) are depicted in a simplified manner: 1, Full-length and/or fragments of $n E$ ErbB receptors could act as transcription factors or transcriptional co-activators. 2, nErbB receptors could arbitrate chromatin remodeling. 3, Activated nErbB receptors, perhaps with the concurrence of their ligands, could phosphorylate nuclear proteins. 4, $\mathrm{nErbB}$ receptors associated to the nucleoli could regulate transcription of rRNA genes, and/or modulate mRNAs and/or rRNAs processing.

tional power between different EGFR segments ${ }^{35}$. Alternatively, further intranuclear proteolytic processing of the EGFR could release the C-terminal segment with the highest transcriptional activity ${ }^{14}$. Nevertheless, as signal transducer and activator of transcription (STAT) proteins bind to EGFR, it cannot be excluded that nuclear co-translocation of an EGFR/STAT complex, or other EGFR/protein complexes, could be responsible for additional transcriptional events.

The potential transcriptional role of nuclear ErbB2 has also been documented ${ }^{43}$. Hence, the cytoplasmic domain of ErbB2 fused to the DNA-binding domain of GAL4 acts as a transcriptional activator in yeast and mammalian cells, and the C-terminal domain of the receptor (residues 1075-1260) was shown to be responsible of its transcriptional activity ${ }^{43}$. It has been also suggested that the ErbB4 cytoplasmic domain, or a segment of its C-terminal region released upon further intranuclear proteolytic processing, may also intervene in gene transcription ${ }^{28,46}$.

A sustained increase in tyrosine phosphorylation of nuclear proteins upon EGF treatment, presumably carried out at least in part by nuclear EGFR, has been demonstrated in different cell lines, particularly at the nucleoli ${ }^{39,40}$, where their possible involvement in 
RNA processing has been suspected ${ }^{39}$. This agrees with our observation on the association of EGFR-GFP to the nucleoli (fig. 2). In addition, it has been suggested that phosphorylation events could regulate the transcriptional activity of nuclear ErbB4 ${ }^{28}$.

Interesting, the EGFR is able to phosphorylate calmodulin in the presence but not in the absence of a basic protein cofactor, such as histones ${ }^{52,59,60}$. Although the use of histones in our earlier in vitro phosphorylation experiments was not considered to have a physiological meaning, the observed translocation of EGFR into the nucleus has persuaded us to reconsider the possibility that calmodulin could be phosphorylated in intact cells by the nuclear receptor with the concurrence of histones ${ }^{61}$.

Nuclear EGFR dephosphorylation could be carried out by a few protein-tyrosine phosphatases located in the nucleus, including the TC45 form of the T-cell protein tyrosine phosphatase (TCPTP) ${ }^{62}$. TC45 exits the nucleus upon addition of EGF, and dephosphorylates several cytosolic phosphoproteins and the membrane bound EGFR, resulting in its inactivation ${ }^{63}$. Nevertheless, this does not exclude that, additionally, nuclear TC45 could be involved in the dephosphorylation of the EGFR located in the nucleus.

Because the surface-restricted EGFR is fully mitogenic, it has been suggested that the nuclear receptor could have an antimitogenic rather than a mitogenic function ${ }^{14,50}$. Likewise, this has also been suggested for the nuclear translocated cytosolic domain of ErbB4 ${ }^{28,29}$. Moreover, it has been proposed that different ligands could potentially direct distinct functions of the nuclear EGFR ${ }^{14}$.

The translocation of ErbB receptors into the nucleus appears to be a reversible process, exiting to the cytoplasm after their intranuclear functional roles are accomplished. In this context, it is interesting to mention that three putative nuclear export signal (NES) consensus sequences have been identified in the cytosolic domain of ErbB4 ${ }^{46}$. No information is yet available, however, on the occurrence of NES sequences in other ErbB receptors, although ErbB3 has been shown to move from the nucleoplasm to the cytoplasm in a HRGß1-dependent manner ${ }^{25}$.

\section{TARGETING NUCLEAR ErbB RECEPTORS: THERAPEUTIC IMPLICATIONS}

Human tumor cells overexpressing ErbB receptors have been targeted with specific anti-ErbB antibodies and chemical tyrosine kinase inhibitors to block their malignant growth ${ }^{64-67}$. The realization that ErbB receptors and their ligands are able to be translocated to the nucleus open the possibility to develop new drugs that could be used to specifically inhibit the nuclear functions of these receptors 27 . Theoretically, it could be possible to intervene at several points of the nuclear cycle of ErbB receptors and/or their ligands, such as inhibiting their entry into or exit from the nucleus, or their intranuclear functions. In this context, a recent report shows that the nuclear translocation of $\left[{ }^{111} \mathrm{In}\right] \mathrm{EGF}$ induces radiotoxicity on human breast cancer cells overexpressing EGFR, significantly inhibiting its growth rate ${ }^{68}$. It is expected that an important research effort would be performed in this regard in the near future. Nevertheless, more detailed information about the submerge molecular mechanisms responsible for the nuclear translocation process as well as the actual functional roles of ErbB receptors and their ligands at the nucleus, must be available to credit the significance of these findings. If this is eventually accomplished, the successful development of therapeutic strategies of clinical relevance could be achieved.

\section{NOTE ADDED IN PROOF}

Recently, another review describing the nuclear localization and functions of tyrosine kinase receptors, with special emphasis on ErbB4, has appeared ${ }^{69}$.

\section{ACKNOWLEDGMENTS}

The work in the authors laboratory was financed by grants (to $\mathrm{AV}$ ) from the Comisión Interministerial de Ciencia y Tecnología (SAF2002-03258), the Consejería de Educación de la Comunidad de Madrid (08.1/0027/2001-1), and the Agencia Española de Cooperación Internacional (2002CN0013). The generous support of the Instituto Carlos III, Fondo de Investigaciones Sanitarias (RTICCC C03/10) is also acknowledged. We thank Dr. Carlos Enrich (Universitat de Barcelona) for the generous gift of PAE/EGFR-GFP cells.

\section{References}

1. Weiss A, Schlessinger J. Switching signals on or off by receptor dimerization. Cell 1998;94:277-80.

2. Hubbard SR, Till JH. Protein tyrosine kinase structure and function. Annu Rev Biochem 2000;69:373-98.

3. Carraway KL III, Sweeney C. Localization and modulation of erbB receptor tyrosine kinases. Curr Op Cell Biol 2001;13:125-30.

4. Alroy I, Yarden Y. The ErbB signaling netwok in embriogenesis and oncogenesis: signal diversification through combinatorial ligand-receptor interactions. FEBS Lett 1997;410:83-6.

5. Citri A, Skaria KB, Yarden Y. The deaf and the dumb: the biology of ErbB-2 and ErbB-3. Exp Cell Res 2003;284: 54-65.

6. Kim H, Muller WJ. The role of the epidermal growth factor receptor family in mammary tumorigenesis and metastasis. Exp Cell Res 1999;253:78-87.

7. Olayioye MA, Neve RM, Lane HA, et al. The ErbB signaling network: receptor heterodimerization in development and cancer. EMBO J 2000;19:3159-67.

8. Fantl WJ, Johnson DE, Williams LT. Signalling by receptor tyrosine kinases. Annu Rev Biochem 1993;62:453-81. 
9. Schlessinger J. Cell signaling by receptor tyrosine kinases. Cell 2000;103:211-25.

10. Waterman H, Yarden Y. Molecular mechanisms underlying endocytosis and sorting of ErbB receptor tyrosine kinases. FEBS Lett 2001;490:142-52.

11. Wang Y, Pennock S, Chen X, et al. Endosomal signaling of epidermal growth factor receptor stimulates signal transduction pathway leading to cell survival. Mol Cell Biol 2002;22:7279-90.

12. Jans DA. Nuclear signaling pathways for polypeptide ligands and their membrane receptors? FASEB J 1994; 8:841-7.

13. Pederson T. Growth factors in the nucleolus? J Cell Biol 1998;143:279-81.

14. Wells A, Marti U. Signalling shortcuts: cell-surface receptors in the nucleus? Nat Rev Mol Cell Biol 2002; 3:697-702.

15. Johnson LK, Vlodavsky I, Baxter JD, et al. Nuclear accumulation of epidermal growth factor in cultured rat pituitary cells. Nature 1980;287:340-3.

16. Rakowicz-Szulczynska EM, Rodeck U, Herlyn M, et al. Chromatin binding of epidermal growth factor, nerve growth factor, and platelet-derived growth factor in cells bearing the appropriate surface receptors. Proc Natl Acad Sci USA 1986;83:3728-32.

17. Raper SE, Burwen SJ, Barker ME, et al. Translocation of epidermal growth factor to the hepatocyte nucleus during rat liver regeneration. Gastroenterology 1987;92:1243-50.

18. Rakowicz-Szulczynska EM, Otwiaska D, Rodeck U, et al. Epidermal growth factor (EGF) and monoclonal antibody to cell surface EGF receptor bind to the same chromatin receptor. Arch Biochem Biophys 1989; 268:45664.

19. Jiang LW, Schindler M. Nucleocytoplasmic transport is enhanced concomitant with nuclear accumulation of epidermal growth factor (EGF) binding activity in both 3T3-1 and EGF receptor reconstituted NR-6 fibroblasts. J Cell Biol 1990;10:559-68.

20. Marti U, Burwen SJ, Wells A, et al. Localization of epidermal growth factor receptor in hepatocyte nuclei. Hepatology 1991;13:15-20.

21. Marti U, Ruchti C, Kampf J, et al. Nuclear localization of epidermal growth factor and epidermal growth factor receptors in human thyroid tissues. Thyroid 2001; 11:137-45.

22. Modrell B, McDonald VL, Shoyab M. The interaction of amphiregulin with nuclei and putative nuclear localization sequence binding proteins. Growth Factors 1992; 7:305-14.

23. Kimura H. Schwannoma-derived growth factor must be transported into the nucleus to exert its mitogenic activity. Proc Natl Acad Sci USA 1993;90:2165-9.

24. Li W, Park JW, Nuijens A, et al. Herregulin is rapidly translocated to the nucleus and its transport is correlated with c-myc induction in breast cancer cells. Oncogene 1996;12:2473-7.

25. Offterdinger M, Schofer C, Weipoltshammer K, et al. cerbB-3: a nuclear protein in mammary epithelial cells. J Cell Biol 2002;157:929-39.

26. Johnson GR, Saeki T, Auersperg N, et al. Response to and expression of amphiregulin by ovarian carcinoma and normal ovarian surface epithelial cells: nuclear localization of endogenous amphiregulin. Biochem Biophys Res Commun 1991;180:481-8.

27. Waugh MG, Hsuan JJ. EGF receptors as transcription factors: ridiculous or sublime? Nat Cell Biol 2001;3: E209-11.

28. Heldin C-H, Ericsson J. RIPping tyrosine kinase receptors apart. Science 2001;294:2111-3.
29. Raben DM, Baldassare JJ. More than scratching the surface: mitogen receptors as transcription factors? Trends Endocrinol Metabol 2002;13:93-4.

30. Mroczkowski B, Mosig G, Cohen S. ATP-stimulated interaction between epidermal growth factor receptor and supercoiled DNA. Nature 1984;309:270-3.

31. Basu M, Frick K, Sen-Majumdar A, et al. EGF receptorassociated DNA-nicking activity is due to a Mr-100,000 dissociable protein. Nature 1985;316:640-1.

32. Carpentier JL, Rees AR, Gregoriou M, et al. Subcellular distribution of the external and internal domains of the EGF receptor in A-431 cells. Exp Cell Res 1986;166:312-26.

33. Marti U, Hug M. Acinar and cellular distribution and mRNA expression of the epidermal growth factor receptor are changed during liver regeneration. J Hepatol 1995;23:318-27.

34. Zimmermann H, Ganz P, Zimmermann A, et al. The overexpression of proliferating cell nuclear antigen in biliary cirrhosis in the rat and its relationship with epidermal growth factor receptor. J Hepatol 1995;23:459-64.

35. Lin S-Y, Makino K, Xia WY, et al. Nuclear localization of EGF receptor and its potential new role as a transcription factor. Nat Cell Biol 2001;3:802-8.

36. Kamio T, Shigematsu K, Sou H, et al. Immunohistochemical expression of epidermal growth factor receptors in human adrenocortical carcinoma. Hum Pathol 1990;21:277-82.

37. Lipponen P, Eskelinen M. Expression of epidermal growth factor receptor in bladder cancer as related to established prognostic factors, oncoprotein (c-erbB-2, p53) expression and long-term prognosis. Br J Cancer 1994;69:1120-5.

38. Tervahauta A, Syrjanen S, Syrjanen K. Epidermal growth factor receptor, c-erbB-2 proto-oncogene and estrogen receptor expression in human papillomavirus lesions of the uterin cervix. Int J Gynecol Pathol 1994; 13:234-40.

39. Holt SJ, Alexander P, Inman CB, et al. Epidermal growth factor induced tyrosine phosphorylation of nuclear proteins associated with translocation of epidermal growth factor receptor into the nucleus. Biochem Pharmacol 1994;47:117-26.

40. Holt SJ, Alexander P, Inman CB, et al. Ligand-induced translocation of epidermal growth factor receptor to the nucleus of NR6/HER fibroblasts is serum dependent. Exp Cell Res 1995;217:554-8.

41. Oksvold M, Huitfeldt H, Stang E, et al. Localizing the EGF receptor. Nat Cell Biol 2002;4:E22.

42. Bourguignon L, Lan K-H, Singleton P, et al. Localizing the EGF receptor - Reply. Nat Cell Biol 2002;4:E22-3.

43. Xie Y, Hung MC. Nuclear localization of $p 185^{\text {neu }}$ tyrosine kinase and its association with transcriptional transactivation. Biochem Biophys Res Commun 1994;203:1589-98.

44. Srinivasan R, Poulsom R, Hurst HC, et al. Expression of the c-erbB-4/HER4 protein and mRNA in normal human fetal and adult tissues and in a survey of nine solid tumour types. J Pathol 1998;185:236-45.

45. Srinivasan R, Gillett CE, Barnes DM, et al. Nuclear expression of the c-erbB-4/HER-4 growth factor receptor in invasive breast cancers. Cancer Res 2000; 60:1483-7.

46. Ni C-Y, Murphy MP, Golde TE, et al. $\gamma$-Secretase cleavage and nuclear localization of ErbB-4 receptor tyrosine kinase. Science 2001;294:2179-81.

47. Lee H-J, Jung K-M, Huang YZ, et al. Presenilin-dependent $\gamma$-secretase-like intramembrane cleavage of ErbB4. J Biol Chem 2002;277:6318-23.

48. Takasugi N, Tomita T, Hayashi I, et al. The role of presenilin cofactors in the g-secretase complex. Nature 2003; 422:438-41. 
49. Bargmann CI, Hyung MC, Weinberg RA. Multiple independent activations of the neu oncogene by a point mutation altering the transmembrane domain of p185. Cell 1986;45:649-57.

50. Marti U, Wells A. The nuclear accumulation of variant epidermal growth factor receptor (EGFR) lacking the transmembrane domain requires coexpression of a fulllength EGFR. Mol Cell Biol Res Commun 2000;3:8-14.

51. Sweitzer TD, Hanover JA. Calmodulin activates nuclear protein import: a link between signal transduction and nuclear transport. Proc Natl Acad Sci USA 1996; 93:14574-9.

52. San José E, Benguría A, Geller P, Villalobo A. Calmodulin inhibits the epidermal growth factor receptor tyrosine kinase. J Biol Chem 1992;267:15237-45.

53. Martín-Nieto J, Villalobo A. The human epidermal growth factor receptor contains a juxtamembrane calmodulin-binding site. Biochemistry 1998;37:227-36.

54. Aifa S, Johansen K, Nilsson UK, et al. Interactions between the juxtamembrane domain of the EGFR and calmodulin measured by surface plasmon resonance. Cell Signal 2002;14:1005-13.

55. Li H, Villalobo A. Evidence for the direct interaction between calmodulin and the human epidermal growth factor receptor. Biochem J 2002;362:499-505.

56. Tebar F, Villalonga P, Sorkina T, et al. Calmodulin regulates intracellular trafficking of epidermal growth factor receptor and the MAPK signaling pathway. Mol Biol Cell 2002;13:2057-68.

57. Martín-Nieto J, Cusidó-Hita DM, Li H, et al. Regulation of ErbB receptors by calmodulin. Rec Res Develop Biochem 2002;3:41-58.

58. Antonsson A, Hughes K, Edin S, et al. Regulation of cRel nuclear localization by binding of $\mathrm{Ca}^{2+} /$ calmodulin. Mol Cell Biol 2003;23:1418-27.
59. Benguría A, Hernández-Perera O, Martínez-Pastor MT, et al. Phosphorylation of calmodulin by the epidermalgrowth-factor-receptor tyrosine kinase. Eur J Biochem 1994;224:909-16.

60. Villalobo A, Ruano MJ, Palomo-Jiménez PI, et al. The epidermal growth factor receptor and the calcium signal. In: Pochet R, et al. editors. Calcium: the molecular basis of calcium action in biology and medicine. Boston MA: Kluwer Academic Publishers, 2000;pp.287-303.

61. Benaim G, Villalobo A. Phosphorylation of calmodulin: functional implications. Eur J Biochem 2002;269:3619-31.

62. Bollen M, Beullens M. Signaling by protein phosphatases in the nucleus. Trends Cell Biol 2002;12:138-45.

63. Tiganis T, Bennett AM, Ravichandran KS, et al. Epidermal growth factor receptor and the adaptor protein p52 $2^{\text {Shc }}$ are specific substrates of T-cell protein tyrosine phosphatase. Mol Cell Biol 1998;18:1622-34.

64. Mendelsohn J, Baselga J. The EGF receptor family as targets for cancer therapy. Oncogene 2000;19:6550-65.

65. Noonberg SB, Benz CC. Tyrosine kinase inhibitors targeted to the epidermal growth factor receptor subfamily: role as anticancer agents. Drugs 2000;59:753-67.

66. Yarden Y. The EGFR family and its ligands in human cancer: signalling mechanisms and therapeutic opportunities. Eur J Cancer 2001;37:S3-8.

67. Zwick E, Bange J, Ullrich A. Receptor tyrosine kinases as targets for anticancer drugs. Trends Mol Med 2002; 8:17-23.

68. Reilly RM, Kiarash R, Cameron RG, et al. ${ }^{111}$ In-labeled EGF is selectively radiotoxic to human breast cancer cells overexpressing EGFR. J Nucl Med 2000;41:429-38.

69. Carpenter G. Nuclear localization and possible functions of receptor tyrosine kinases. Curr Op Cell Biol 2003; 15:143-8. 